University of Nebraska - Lincoln

DigitalCommons@University of Nebraska - Lincoln

\title{
Estimation of chlorophyll-a concentration in turbid productive waters using airborne hyperspectral data
}

Wesley J. Moses

Center for Advanced Land Management Information Technologies (CALMIT), University of NebraskaLincoln,wmoses.unl@gmail.com

Anatoly Gitelson Center for Advanced Land Management Information Technologies (CALMIT), University of NebraskaLincoln, agitelson2@unl.edu

Richard L. Perk Center for Advanced Land Management Information Technologies (CALMIT), University of NebraskaLincoln, rperk1@unl.edu

Daniela Gurlin Center for Advanced Land Management Information Technologies (CALMIT), University of NebraskaLincoln

Donald C. Rundquist Center for Advanced Land Management Information Technologies (CALMIT), University of NebraskaLincoln

Follow this and additional works at: https://digitalcommons.unl.edu/natrespapers

se next page for additional authors

Part of the Environmental Monitoring Commons, Natural Resources and Conservation Commons, and the Water Resource Management Commons

Moses, Wesley J.; Gitelson, Anatoly; Perk, Richard L.; Gurlin, Daniela; Rundquist, Donald C.; Leavitt, Bryan C.; Barrow, Tadd M.; and Brakhage, Paul, "Estimation of chlorophyll-a concentration in turbid productive waters using airborne hyperspectral data" (2012). Papers in Natural Resources. 313.

https://digitalcommons.unl.edu/natrespapers/313

This Article is brought to you for free and open access by the Natural Resources, School of at DigitalCommons@University of Nebraska - Lincoln. It has been accepted for inclusion in Papers in Natural Resources by an authorized administrator of DigitalCommons@University of Nebraska - Lincoln. 
Authors

Wesley J. Moses, Anatoly Gitelson, Richard L. Perk, Daniela Gurlin, Donald C. Rundquist, Bryan C. Leavitt, Tadd M. Barrow, and Paul Brakhage 


\title{
Estimation of chlorophyll-a concentration in turbid productive waters using airborne hyperspectral data
}

\author{
Wesley J. Moses ${ }^{a, b, 1}$, Anatoly A. Gitelson ${ }^{a, b, *}$, Richard L. Perk ${ }^{a, b}$, Daniela Gurlin ${ }^{a, b}$, \\ Donald C. Rundquist $^{a, b}$, Bryan C. Leavitt ${ }^{a, b}$, Tadd M. Barrow ${ }^{b}$, Paul Brakhage $^{c}$ \\ ${ }^{a}$ Center for Advanced Land Management Information Technologies (CALMIT), University of Nebraska-Lincoln, 303 Hardin Hall, Lincoln, USA \\ ${ }^{\mathrm{b}}$ School of Natural Resources, University of Nebraska-Lincoln, USA \\ ${ }^{\mathrm{c}}$ Nebraska Department of Environmental Quality, Lincoln, NE, USA
}

\section{A R T I C L E I N F O}

Article history:

Received 28 June 2011

Received in revised form

10 November 2011

Accepted 25 November 2011

Available online 16 December 2011

Keywords:

Remote sensing

Near infra-red

Chlorophyll-a

Atmospheric correction

QUAC

FLAASH

AISA

\begin{abstract}
A B S T R A C T
Algorithms based on red and near infra-red (NIR) reflectances measured using field spectrometers have been previously shown to yield accurate estimates of chlorophylla concentration in turbid productive waters, irrespective of variations in the bio-optical characteristics of water. The objective of this study was to investigate the performance of NIR-red models when applied to multi-temporal airborne reflectance data acquired by the hyperspectral sensor, Airborne Imaging Spectrometer for Applications (AISA), with non-uniform atmospheric effects across the dates of data acquisition. The results demonstrated the capability of the NIR-red models to capture the spatial distribution of chlorophyll- $a$ in surface waters without the need for atmospheric correction. However, the variable atmospheric effects did affect the accuracy of chlorophyll-a retrieval. Two atmospheric correction procedures, namely, Fast Line-of-sight Atmospheric Adjustment of Spectral Hypercubes (FLAASH) and QUick Atmospheric Correction (QUAC), were applied to AISA data and their results were compared. QUAC produced a robust atmospheric correction, which led to NIR-red algorithms that were able to accurately estimate chlorophyll-a concentration, with a root mean square error of $5.54 \mathrm{mg} \mathrm{m}^{-3}$ for chlorophylla concentrations in the range $2.27-81.17 \mathrm{mg} \mathrm{m}^{-3}$.
\end{abstract}

(c) 2011 Elsevier Ltd. All rights reserved.

\section{Introduction}

Inland, estuarine, and coastal waters represent complex and highly variable ecosystems, which sustain a wide variety of aquatic flora and fauna, and are critical to preserving global biodiversity (Revenga and Kura, 2003). Aquatic environments are also of immense recreational and economic value to humans. Nevertheless, in recent years, these ecosystems have been experiencing increased stress due to factors that are primarily of anthropogenic origin, and have consequently become some of the most threatened ecosystems on Earth. Therefore, it is important that the biogeochemical condition of these waters is regularly monitored. Chlorophyll-a (chl-a) concentration is a strong indicator of the trophic status of a water body (e.g., Schalles et al., 1998; Honeywill et al., 2002) and quantifying the concentration of chl- $a$ in a water body is a standard way of monitoring its biogeochemical status.

\footnotetext{
* Corresponding author. Center for Advanced Land Management Information Technologies (CALMIT), University of Nebraska-Lincoln, 303 Hardin Hall, Lincoln, USA. Tel.: +1 402472 8386; fax: +1 4024722946.

E-mail addresses: wesley.moses.ctr.in@nrl.navy.mil (W.J. Moses), agitelson2@unl.edu (A.A. Gitelson).

${ }^{1}$ Present address: National Research Council, Naval Research Laboratory, Washington, D.C. 20375, USA. 0043-1354/\$ - see front matter @ 2011 Elsevier Ltd. All rights reserved. doi:10.1016/j.watres.2011.11.068
} 
Remote sensing is a very useful tool for monitoring water quality. Remote sensing using airborne sensors has several advantages over remote sensing using spaceborne sensors in monitoring inland, estuarine, and coastal waters. Most inland water bodies are too small in their spatial extent to be monitored by means of current spaceborne satellites. The proximity of the shore often makes it difficult to retrieve pure water pixels from satellite data acquired over estuarine and coastal waters. Airborne sensors, however, can have variable, much finer spatial resolutions as compared to spaceborne sensors that have a fixed, coarser resolution. For instance, the airborne AISA-Eagle (Airborne Imaging Spectrometer for Applications) has a spatial resolution that varies with altitude and can be as fine as $0.5 \mathrm{~m} \times 0.5 \mathrm{~m}$ at an altitude of about $0.75 \mathrm{~km}$ above ground, whereas spaceborne satellites MODIS (MODerate resolution Imaging Spectroradiometer) and MERIS (MEdium Resolution Imaging Spectrometer) have spatial resolutions of $1 \mathrm{~km} \times 1 \mathrm{~km}$ and $260 \mathrm{~m} \times 290 \mathrm{~m}$, respectively. Thus, the higher spatial resolution offered by airborne sensors make them better suited for these water bodies. Satellite sensors with very high spatial resolutions (e.g., IKONOS, QuickBird, and GeoEye) lack the spectral resolution and sensitivity required for quantitatively estimating chla concentration in optically complex waters. The spaceborne Hyperion has high spatial and spectral resolutions but its 16 day revisit cycle is too long for continuous regular monitoring of water bodies.

Another advantage of most airborne sensors is that they are programmable, i.e., the number and locations of spectral channels and their bandwidths are adjustable. Thus, it is possible to designate spectral channels centered at specific wavelengths (e.g., Kallio et al., 2001) and at desired spectral resolutions (e.g., as fine as $2.9 \mathrm{~nm}$ for AISA-Eagle). The control on the timing of data acquisition enables collecting data at optimal time periods and helps in mitigating adverse weather conditions such as cloud cover and haze, which often hinder reliable data collection from spaceborne sensors. Airborne remote sensing, however, also has some limitations when compared to spaceborne remote sensing. The geographical coverage from an airborne platform is much smaller than what can be covered from a spaceborne platform. Depending on the prevailing atmospheric conditions, the airborne platform can be quite unsteady, resulting in geometric distortions in the image that can be difficult to correct. There is a high cost associated with every airborne data acquisition. Nevertheless, airborne remote sensing can still be a very useful tool for monitoring specific inland, estuarine, and coastal waters on a regular basis.

Inland, estuarine, and coastal waters that receive input of terrigenous nutrients are typically turbid and productive. These Case II waters (Morel and Prieur, 1977) are optically complex. Specifically, suspended solids and colored dissolved organic matter (CDOM) occur in relative abundance in these waters when compared to ocean waters, and their concentrations do not co-vary with chl-a concentration. Moreover, suspended solids and CDOM have overlapping absorption features in the blue spectral region. As a result, chl- $a$ is not the sole factor dominating the optical properties of these waters. Hence, the standard open-ocean algorithms that rely on reflectances in the blue and green spectral regions (e.g.,
Gordon and Morel, 1983; Gordon et al., 1988; O'Reilly et al., 1998; O'Reilly et al., 2000) do not yield accurate estimates of chl-a concentration in these waters (e.g., Carder et al., 2004; Darecki and Stramski, 2004; Dall'Olmo et al., 2005).

Algorithms that use reflectances in the red and near infrared (NIR) regions are preferable for turbid productive waters because the absorption by suspended solids and CDOM are very low in these regions (Gitelson and Kondratyev, 1991; Gitelson, 1992; Dekker, 1993; Han and Rundquist, 1997; Gons, 1999; Gower et al., 1999; Ruddick et al., 2001; Dall'Olmo et al., 2005). NIR-red algorithms take advantage of a local minimum in reflectance around $670 \mathrm{~nm}$ due to absorption by chl- $a$ and a local maximum of reflectance around $700 \mathrm{~nm}$, which is due to the combination of diminishing absorption by chl- $a$ and increasing absorption by water (Vasilkov and Kopelevich, 1982; Gitelson, 1992; Han et al., 1994).

The three-band NIR-red model (Dall'Olmo et al., 2003; Dall'Olmo and Gitelson, 2005):

Chl- $a \propto\left(R_{\lambda_{1}}^{-1}-R_{\lambda_{2}}^{-1}\right) \times R_{\lambda_{3}}$

and the two-band NIR-red model (Gitelson, 1992):

Chl- $a \propto R_{\lambda_{1}}^{-1} \times R_{\lambda_{2}}$

(where $R_{\lambda_{i}}$ is the reflectance at wavelength $\lambda_{i} \mathrm{~nm}$ ) have been shown to consistently yield accurate estimates of chl-a concentration for water bodies with widely varying biogeochemical characteristics and from different geographical locations. These models have been developed and validated using data acquired by field spectrometers (Gitelson, 1992; Dall'Olmo and Gitelson, 2005; Gitelson et al., 2008, 2009; Yacobi et al., 2011; Gurlin et al., 2011), satellites (Moses, 2009; Moses et al., 2009b) and data simulated using the radiative transfer model, Hydrolight (Gilerson et al., 2010). The optimal spectral ranges for the location of these wavelengths were found to be, $\lambda_{1}=660-670 \mathrm{~nm}, \lambda_{2}=700-730 \mathrm{~nm}$, and $\lambda_{3}=740-760 \mathrm{~nm}$ (Dall'Olmo and Gitelson, 2005; Gitelson et al., 2008).

Koponen et al. (2002) and Kallio et al. (2001) applied several empirical NIR-red algorithms to estimate chl-a concentration in several lakes in Finland using AISA data and discovered that the performance of the algorithms they tested varied seasonally. Such seasonal variations preclude algorithms from being used operationally in a routine manner for data from different seasons and different geographic locations. The seasonal variations could be due to the inability of the algorithms in their specific parameterized forms to account for seasonal changes in the biogeochemical characteristics of water or due to variations in the atmospheric effects on the images collected in different seasons, which were not accurately removed. However, the three-band and two-band NIRred models (Equations (1) and (2)) have been previously shown to yield accurate estimates of chl-a concentration irrespective of seasonal changes in the biogeochemical properties of water (e.g., Dall'Olmo and Gitelson, 2005; Gitelson et al., 2008; Moses et al., 2009b; Gilerson et al., 2010; Gurlin et al., 2011; Yacobi et al., 2011), and it is of interest to investigate their sensitivity to variations in atmospheric effects. In this study, we have applied these NIR-red models (Equations (1) and (2)) to multi-temporal airborne hyperspectral reflectance data 
acquired by the AISA-Eagle hyperspectral sensor over several inland water bodies in the Midwestern United States and investigated the performances of the models by addressing the following questions:

(i) How is the relationship between the NIR-red model values and chl-a concentrations affected by the variable atmospheric effects associated with imagery acquired on different days?

(ii) After a reliable correction for the non-uniform atmospheric effects, how does the accuracy of chl-a concentration estimated by the NIR-red algorithms from the airborne reflectance data compare to that retrieved from reflectances measured in situ using a field spectrometer?

\section{Material and methods}

Both airborne and in situ data were collected at the Fremont Lakes in Nebraska, USA, during the summer and fall of 2008. The lakes are located in the Fremont State Lakes Recreational Area, situated about $4.82 \mathrm{~km}$ west of Fremont, Nebraska, in the PlatteRiver valley. The lakes were a result of sand and gravel mining in the 1930's, and they currently comprise nearly 121 ha of water. The lakes attract thousands of visitors annually and are of high recreational value to Eastern Nebraska. The water quality in the Fremont Lakes is monitored by the Nebraska Department of Environmental Quality (NDEQ) and problems related to total phosphorus, total nitrogen and chl-a concentrations are of significant concern for several of the Fremont Lakes (NDEQ Water Quality Division, 2010). From 2004 to 2006, one of the most popular lakes for recreational activities was closed for 25 weeks due to the presence of algal toxins. The lake was treated with aluminum sulfate in 2007 to reduce the phosphorus concentration and biological productivity of the lake. In 2008, the productivity was significantly reduced and the lake contained only moderate chl-a concentrations at the time of field data collection. The Fremont Lakes provide a wide range of biogeochemical conditions that are typically encountered in turbid productive inland, estuarine, and coastal waters, which makes these lakes ideal for the investigation of NIR-red algorithms for the remote estimation of chl-a concentration in Case II waters.

\subsection{Airborne reflectance measurements}

Five images were acquired over the Fremont Lakes using the AISA-Eagle hyperspectral sensor, mounted in a Piper Saratoga aircraft that was flown at an altitude of about $3 \mathrm{~km}$ above ground. The images were acquired on 02 July, 14 July, 26 September, 25 October, and 19 November of 2008.

The AISA-Eagle is a programmable imaging spectrometer. A maximum of 256 continuous spectral channels are possible in the 400-970 nm wavelength range, with a spectral resolution as fine as $2.9 \mathrm{~nm}$. The central wavelength location and the bandwidth of the spectral channels are programmable, enabling the acquisition of data with the desired spectral characteristics based on the specific requirements for the research. The sensor has a peak signal-to-noise ratio of 490 , obtained for a typical vegetation target. At a flight altitude of about $3 \mathrm{~km}$ above ground, the sensor acquires data at a spatial resolution of $2 \mathrm{~m}$. More detailed information on the sensor characteristics can be obtained at www.specim.fi. The images used in this research had a spectral resolution of $10 \mathrm{~nm}$ and a spatial resolution of $2 \mathrm{~m}$.

\subsection{In situ reflectance measurements}

In situ reflectance measurements were taken on the lakes to coincide with AISA image acquisitions on all five dates, except for 25 Oct 2008 when the in situ data were collected a day earlier (on 24 Oct). The field measurements were collected from a total of 34 stations in 9 different, though closely located, lakes (Table 2).

Two inter-calibrated Ocean Optics ${ }^{\circledR}$ USB 2000 spectrometers, deployed from a boat, were used to measure upwelling radiance from the water and downwelling irradiance in the range 400-900 $\mathrm{nm}$. The sampling interval of the spectrometers was $0.3 \mathrm{~nm}$, with a spectral resolution of $1.5 \mathrm{~nm}$ and

Table 1 - Descriptive statistics of the optical water quality parameters measured: $a_{\mathrm{p}}(670), a_{\mathrm{NAP}}(670), a_{\varphi}(670)$, and $a_{\mathrm{CDOM}}(670)$ are the absorption coefficients of total particulates, non-algal particles, phytoplankton, and CDOM, respectively, at $670 \mathrm{~nm}$ $a_{0}^{*}(670)$, is the specific absorption coefficient of phytoplankton at $670 \mathrm{~nm}, a_{\text {CDOM }}(440)$ is the absorption coefficient of CDOM at $440 \mathrm{~nm}$.

\begin{tabular}{|c|c|c|c|c|c|c|c|c|}
\hline Parameter & Units & $\begin{array}{c}\text { Number } \\
\text { of samples }\end{array}$ & Min & Max & Median & Mean & $\begin{array}{l}\text { Standard } \\
\text { deviation }\end{array}$ & $\begin{array}{l}\text { Coefficient } \\
\text { of variation }\end{array}$ \\
\hline Chl-a & $\mathrm{mg} \mathrm{m}^{-3}$ & 34 & 2.27 & 81.17 & 20.69 & 26.11 & 20.86 & 0.80 \\
\hline Secchi disk depth & $\mathrm{m}$ & 34 & 0.51 & 4.20 & 1.09 & 1.40 & 0.91 & 0.65 \\
\hline Turbidity & NTU & 34 & 1.51 & 19.20 & 7.22 & 7.93 & 5.28 & 0.67 \\
\hline TSS & $\mathrm{g} \mathrm{m}^{-3}$ & 34 & 1.19 & 15.00 & 6.58 & 7.06 & 3.74 & 0.53 \\
\hline ISS & $\mathrm{g} \mathrm{m}^{-3}$ & 34 & 0.22 & 3.50 & 1.00 & 1.14 & 0.78 & 0.68 \\
\hline Oss & $\mathrm{g} \mathrm{m}^{-3}$ & 34 & 0.81 & 12.50 & 5.89 & 5.93 & 3.35 & 0.57 \\
\hline$a_{p}(670)$ & $\mathrm{m}^{-1}$ & 34 & 0.04 & 2.126 & 0.398 & 0.47 & 0.383 & 0.817 \\
\hline$a_{\text {NAP }}(670)$ & $\mathrm{m}^{-1}$ & 34 & 0.003 & 0.245 & 0.044 & 0.057 & 0.049 & 0.855 \\
\hline$a_{\varphi}(670)$ & $\mathrm{m}^{-1}$ & 34 & 0.047 & 2.104 & 0.374 & 0.412 & 0.377 & 0.915 \\
\hline$a_{\varphi}^{*}(670)$ & $\mathrm{m}^{2} \mathrm{mg}^{-1}$ & 34 & 0.007 & 0.026 & 0.015 & 0.017 & 0.005 & 0.309 \\
\hline$a_{\mathrm{CDOM}}(440)$ & $\mathrm{m}^{-1}$ & 34 & 0.467 & 1.452 & 0.788 & 0.842 & 0.236 & 0.280 \\
\hline$a_{\mathrm{CDOM}}(670)$ & $\mathrm{m}^{-1}$ & 34 & 0.005 & 0.064 & 0.021 & 0.023 & 0.012 & 0.533 \\
\hline
\end{tabular}


Table 2 - Geographical coordinates of stations in the Fremont Lakes where measurements were taken.

\begin{tabular}{lll} 
Lake ID & Latitude & \multicolumn{1}{c}{ Longitude } \\
\hline 1 & $41^{\circ} 27^{\prime} 1.25^{\prime \prime} \mathrm{N}$ & $96^{\circ} 33^{\prime} 37.54^{\prime \prime} \mathrm{W}$ \\
2 & $41^{\circ} 27^{\prime} 0.58^{\prime \prime} \mathrm{N}$ & $96^{\circ} 33^{\prime} 54.63^{\prime \prime} \mathrm{W}$ \\
3 & $41^{\circ} 27^{\prime} 2.74^{\prime \prime} \mathrm{N}$ & $96^{\circ} 34^{\prime} 9.03^{\prime \prime} \mathrm{W}$ \\
4 & $41^{\circ} 27^{\prime} 2.15^{\prime \prime} \mathrm{N}$ & $96^{\circ} 34^{\prime} 37.25^{\prime \prime} \mathrm{W}$ \\
5 & $41^{\circ} 26^{\prime} 57.52^{\prime \prime} \mathrm{N}$ & $96^{\circ} 34^{\prime} 16.09^{\prime \prime} \mathrm{W}$ \\
16 & $41^{\circ} 26^{\prime} 32.01^{\prime \prime} \mathrm{N}$ & $96^{\circ} 33^{\prime} 25.36^{\prime \prime} \mathrm{W}$ \\
17 & $41^{\circ} 26^{\prime} 22.04^{\prime \prime} \mathrm{N}$ & $96^{\circ} 32^{\prime} 43.68^{\prime \prime} \mathrm{W}$ \\
18 & $41^{\circ} 26^{\prime} 17.89^{\prime \prime} \mathrm{N}$ & $96^{\circ} 32^{\prime} 25.23^{\prime \prime} \mathrm{W}$ \\
20 & $41^{\circ} 26^{\prime} 9.61^{\prime \prime} \mathrm{N}$ & $96^{\circ} 32^{\prime} 54.26^{\prime \prime} \mathrm{W}$ \\
\hline
\end{tabular}

a signal-to-noise ratio of 250:1. Spectrometer \#1 was connected to a $25^{\circ}$ field-of-view optical fiber that was taped to a measurement stick and pointed toward nadir to measure the upwelling radiance. The stick was held such that the tip of the optical fiber was just beneath the water surface and as far away from the boat as possible on the sun-lit side in order to avoid light rays reflected from the boat and the effects of the boat shadow. Spectrometer \#2 was connected to an optical fiber that was equipped with a $180^{\circ}$ field-of-view cosine collector that was mounted on a mast and pointed toward zenith at the highest possible spot on the boat such that the cosine collector had a clear $180^{\circ}$ field-of-view of the downwelling irradiance. The upwelling radiance and the downwelling irradiance were recorded simultaneously. At each station, several sets of measurements were taken such that there were at least six virtually identical upwelling radiance spectra, the median of which was taken as the representative spectrum.

Potential differences in the transfer functions of the spectrometers were accounted for by inter-calibrating the spectrometers. Inter-calibration was done by simultaneously measuring the upwelling radiance from a standard white Spectralon ${ }^{\circledR}$ panel with spectrometer \#1 and the corresponding downwelling irradiance incident on the panel with spectrometer \#2.

The remote sensing reflectance was calculated as,

$R_{r s}=\frac{L_{u}}{E_{d}} \frac{E_{\text {cal }}}{L_{\text {cal }}} \frac{R_{\text {cal }}}{\pi} \frac{t}{n^{2}} F_{i}$

where, $L_{u}$ is the upwelling radiance from the water, $E_{d}$ is the downwelling irradiance, $L_{\mathrm{cal}}$ is the upwelling radiance from the calibration panel, $E_{c a l}$ is the downwelling irradiance at the time of calibration measurements, $R_{\text {cal }}$ is the known reflectance of the calibration panel, $\pi$ is used to transform the irradiance reflectance into remote sensing reflectance, $t$ is the transmittance of water (0.98), $n$ is the refractive index of water (1.33), and $F_{i}$ is the immersion factor, which accounts for the difference between the in-air and in-water absolute response of the spectrometer (Austin, 1976; Mueller and Austin, 1995; Zibordi, 2006), and was calculated using the formula used in Ohde and Siegel (2003).

\subsection{Laboratory analysis}

Water samples were collected at each station, kept in a cooler, and analyzed the very same day in the laboratory at the end of in situ data collection. Supplementary in situ measurements included Secchi disk depth, measured with a standard Secchi disk, and turbidity, measured with a $\mathrm{HACH}^{\circledR} 2100$ portable turbidimeter.

Chl-a was extracted from water samples using 99.5\% ethanol at a temperature of $78^{\circ} \mathrm{C}$, and left to cool in the dark for $4 \mathrm{~h}$. The extract was centrifuged for $5 \mathrm{~min}$ in a Cole-Parmer EW-17250-10 fixed-speed centrifuge and the chl-a concentration was determined fluorometrically (Welschmeyer, 1994). The concentrations of inorganic suspended solids (ISS), organic suspended solids (OSS), and total suspended solids (TSS) were determined gravimetrically (Eaton et al., 2005). Particulate absorption coefficients were determined by the quantitative filter technique (Mitchell et al., 2003). The suspended particles were retained by filtering the water samples through $25-\mathrm{mm}$ Whatman GF/F filters and spectral measurements of the optical density were made with a Cary 100 Varian spectrophotometer. The absorption coefficient of CDOM was determined from spectrophotometric measurements of each filtrate. More details of the laboratory analysis procedure can be found in Gitelson et al. (2011) and Gurlin et al. (2011).

The dataset contained concentrations of chl- $a$, TSS, ISS, and OSS, Secchi disk depth, turbidity, and the absorption coefficients of phytoplankton, non-algal particles, total particulates, and CDOM, collected from 34 stations, displaying a wide variation in the concentration of optically active constituents (Table 1).

\subsection{NIR-red models}

The AISA data suffered from instrument noise in the NIR region beyond $730 \mathrm{~nm}$ (where there is high absorption by water). As a result, reflectances at wavelengths beyond $730 \mathrm{~nm}$ were unusable. This meant that $\lambda_{3}$ for the three-band NIR-red model (Eq. (1)) could not be set beyond $730 \mathrm{~nm}$. Previous studies have shown that the two-band NIR-red model (Eq. (2)) with $\lambda_{1}$ and $\lambda_{2}$ set to match the MERIS spectral channels at $665 \mathrm{~nm}$ and $708 \mathrm{~nm}$, respectively, gives accurate results for data simulated by radiative transfer equations (Gilerson et al., 2009, 2010) as well as data acquired by field spectrometers (Gitelson et al., 2008, 2009) and spaceborne sensors (Moses, 2009; Moses et al., 2009a, b).

Considering the aforementioned limitation on $\lambda_{3}$ and choosing AISA spectral channels that were located the closest to the MERIS channels for $\lambda_{1}$ and $\lambda_{2}$, the three-band and twoband NIR-red models for AISA data were formulated as,

Three-band AISA NIR-red Model:

Chl- $a \propto\left(R_{666}^{-1}-R_{704}^{-1}\right) \times R_{723}$

Two-band AISA NIR-red Model:

Chl- $a \propto R_{666}^{-1} \times R_{704}$

where $R_{x}$ is the reflectance in the spectral band centered at wavelength $x \mathrm{~nm}$.

\subsection{Atmospheric correction}

Since the AISA images were collected on different days, spanning a period of about five months, the atmospheric 
conditions could not be assumed to have remained constant across all five dates of image acquisition. Thus it was necessary to correct for the variable atmospheric effects on each image. The AISA data were atmospherically corrected using FLAASH (Fast Line-of-sight Atmospheric Analysis of Spectral Hypercubes) and QUAC (QUick Atmospheric Correction), which were obtained as add-ons to the image processing software, ENVI (Environment for Visualizing Images), from ITT-VIS (International Telephone and Telegraph - Visual Information Solutions).

FLAASH (Adler-Golden et al., 1999; Matthew et al., 2000, 2002) is a 'first-principles' atmospheric correction program, developed based on the radiative transfer code, MODTRAN 4 (MODerate spectral resolution atmospheric TRANsmittance; Berk et al., 2000). First-principles atmospheric correction typically involves three steps: (i) Retrieval of atmospheric parameters (primarily visibility/optical depth, aerosol type, and column water vapor amount), (ii) Solution of the radiative transfer equation using the retrieved/derived atmospheric parameters and conversion of the radiance values into reflectance values, and (iii) Spectral polishing to remove spectral artifacts that may have been introduced during the correction process (Matthew et al., 2002).

FLAASH essentially serves as a user-interface to MODTRAN 4. The program is designed such that the user has limited control over the choice and setting of input parameters for the process. FLAASH is rather simple to execute in terms of the procedure if the user is able to specify appropriate input parameters that characterize the atmospheric conditions and illumination/viewing geometry at the time of image acquisition. Default values or appropriate assumptions (based on theoretical estimates or information from the literature) are used as input parameters when actual measurements are not available. Atmospheric correction is implemented as an iterative process in which the spectral information from the image is used to determine atmospheric parameters. The input parameters that describe the atmosphere serve as initial values that direct the iterative processes toward convergence.
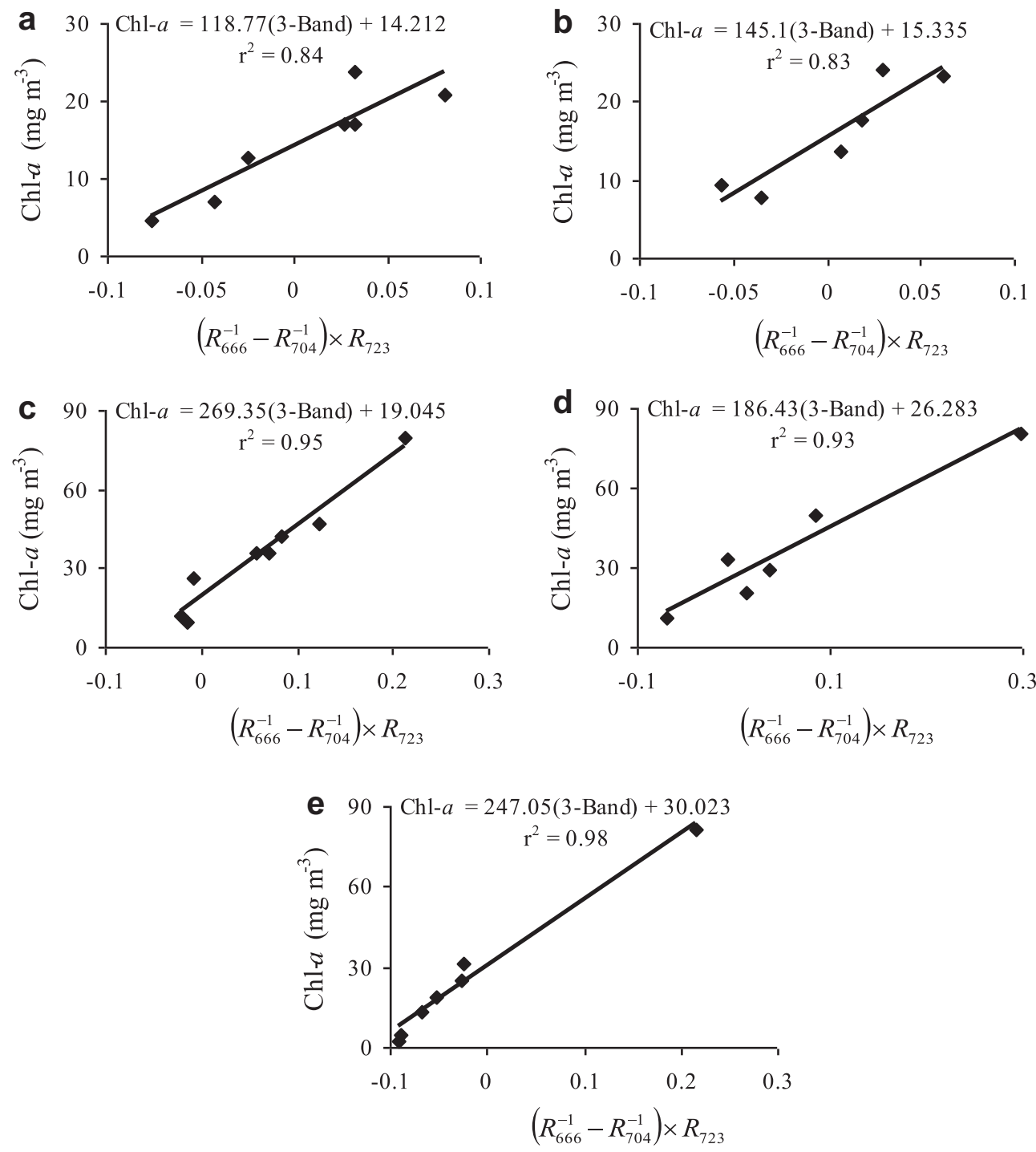

Fig. 1 - Plots of the three-band NIR-red model (applied to AISA at-sensor reflectance) values versus measured chla concentration for (a) 02nd July, (b) 14th July, (c) 26th Sep, (d) 25th Oct, and (e) 19th Nov 2008 data. $R_{x}$ is the reflectance in the spectral band centered at wavelength $x \mathrm{~nm}$. 

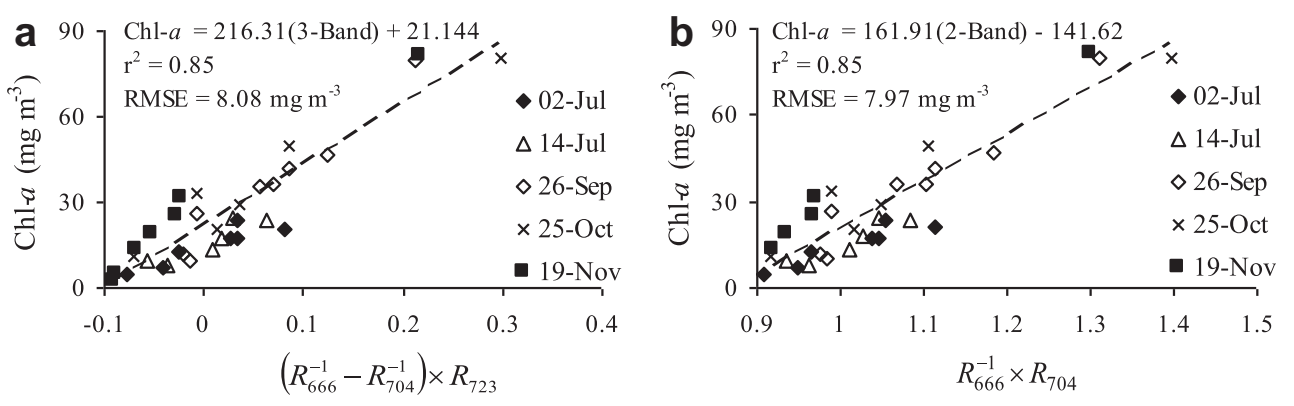

Fig. 2 - (a) Three-band NIR-red and (b) two-band NIR-red model (applied to AISA at-sensor reflectance) values plotted versus measured chl- $a$ concentration for all five campaigns. $R_{x}$ is the reflectance in the spectral band centered at wavelength $x \mathrm{~nm}$.

Accurate input parameters are helpful in achieving quick convergence, by way of reducing the number of iterations, but changing the input parameters does not generally seem to change the spectral shape of the final output reflectance significantly.

QUAC (Bernstein et al., 2005a, b; Bernstein et al., 2006) was developed as a simpler alternative to sophisticated atmospheric correction procedures, such as FLAASH, which are based on radiative transfer models. QUAC is a semi-empirical method that requires no prior information on the ground target or the atmosphere and is based on several simplistic assumptions. The image is assumed to be composed of a reasonable number $(>10)$ of spectrally diverse pixels. The spectral standard deviation of reflectance of the chosen set of diverse pixels is assumed to be a virtually wavelength-independent constant. This assumption is founded on the principle that diverse pixels are not expected to be spectrally correlated and has been empirically validated (Bernstein et al., 2005b). Spurious contributions arising from the atmospheric path radiance and adjacency effects are removed through a baseline correction using dark pixels within the image. Previous results have shown that QUAC yields accuracies that are comparable to those from more sophisticated methods (Bernstein et al., 2005b), with significantly faster computational speeds.

\section{Results and discussion}

\subsection{At-sensor reflectance}

As a first step prior to atmospheric correction, the three-band (Eq. (4)) and two-band (Eq. (5)) NIR-red models were applied to

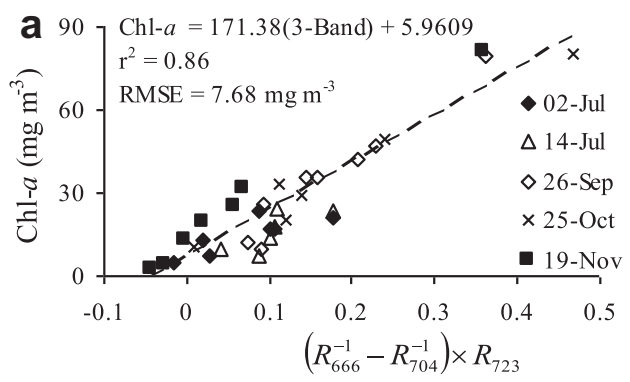

at-sensor reflectances obtained by dividing the at-sensor radiance by the downwelling irradiance recorded at the sensor. The results showed very close linear relationships between NIR-red model values and measured chl- $a$ concentrations. Fig. 1 shows individual plots for the three-band NIR-red model (Eq. (4)). Similar results were obtained for the two-band NIR-red model (Eq. (5), individual plots not shown). For each day, the NIR-red model values had a close relationship (the average coefficient of determination, $r^{2}$, was above 0.90 ) with chl-a concentration, which demonstrated the ability of the NIR-red models to accurately capture the spatial distribution of chl- $a$ concentration within each image in spite of the atmospheric effects on the at-sensor reflectance. This is primarily due to the fact that the atmospheric effects over the lakes, which are located close to each other, are fairly uniform within each image. Moreover, the wavebands in the NIR-red models are located close enough to each other so that the atmospheric effects at these wavebands are alike though not identical and are greatly minimized by the use of reflectance ratios in the models.

However, the slope and intercept of the linear regression between the NIR-red model values and chl-a concentration varied across multiple dates (Fig. 1). Due to these variations, when the multi-temporal data from all stations were plotted together (Fig. 2), a consistently close linear relationship between the chl- $a$ concentrations and NIR-red model values was not evident, which affected the accuracy of quantitative estimates of chl-a concentration. The root mean square errors (RMSEs) of the estimated chl- $a$ concentration were $8.08 \mathrm{mg} \mathrm{m} \mathrm{m}^{-3}$ (nRMSE $=10.24 \%$ ) and $7.97 \mathrm{mg} \mathrm{m} \mathrm{m}^{-3}$ (nRMSE $=10.1 \%$ ) for the three-band (Eq. (4)) and two-band (Eq. (5)) NIR-red models, respectively, where nRMSE is the normalized RMSE, given by,

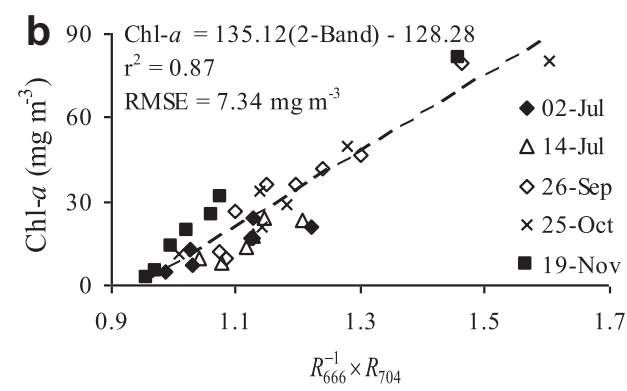

Fig. 3 - Plots of (a) three-band and (b) two-band NIR-red model values versus measured chl-a concentration for the whole dataset after FLAASH correction. $R_{x}$ is the reflectance in the spectral band centered at wavelength $x \mathrm{~nm}$. 

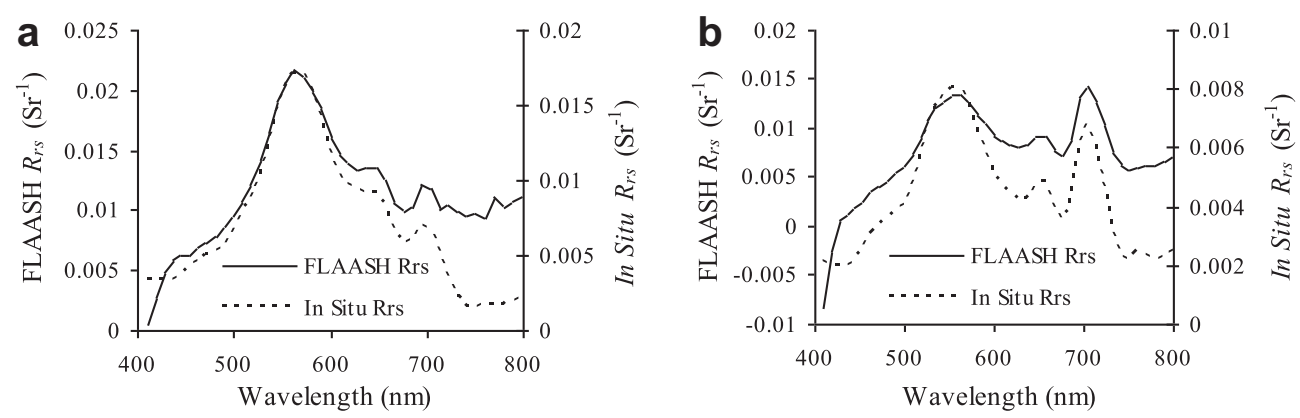

Fig. 4 - FLAASH-corrected AISA reflectance (solid line) and reflectance measured in situ (dotted line) with the Ocean Optics ${ }^{\circledR}$ spectrometer for stations with (a) a moderate chl-a concentration (13.65 $\mathrm{mg} \mathrm{m}^{-3}$ ) and (b) a high chl-a concentration $\left(80.16 \mathrm{mg} \mathrm{m}^{-3}\right)$.

$\mathrm{nRMSE}=\frac{\mathrm{RMSE}}{\left(\mathrm{Chl}-a_{\max }-\mathrm{Chl}-a_{\min }\right)}$

Previous experimental (Gitelson et al., 2008, 2009) and modeling (Dall'Olmo and Gitelson, 2006; Gilerson et al., 2010) results have shown that the NIR-red models are not very sensitive to variations in the biogeochemical characteristics of waters besides chl-a concentration. Thus, the variations in the slope and intercept across the multiple dates (Fig. 1) are likely attributable to differences in the atmospheric effects on the different dates of data acquisition. Such variations are expected to be even larger when the models are applied to multitemporal data from different geographic locations with widely varying atmospheric conditions. Consequently, atmospheric correction was performed on the AISA data to determine if it would result in the convergence of the slopes and intercepts of the relationship between the NIR-red model values and chla concentration across the multiple dates - a critical prerequisite for developing a reliable algorithm for retrieving accurate quantitative estimates of chl-a concentration from a multi-temporal dataset.

\subsection{FLAASH atmospheric correction}

FLAASH was executed on all five AISA images acquired over the Fremont Lakes. Since actual measurements of atmospheric parameters such as the optical depth were not available, all the images were corrected using the same default values for atmospheric input parameters such as visibility
(40 km), aerosol scale height $(2 \mathrm{~km})$, and carbon-dioxide mixing ratio (390 ppm), as defined in FLAASH. Based on the guidelines given in the FLAASH User's Guide (2008), the atmospheric model, which is based on the geographic location and the season of the year at the time of image acquisition, was chosen as 'Mid-Latitude Summer' for the 02 Jul, 14 Jul, 26 Sep, and 25 Oct images, and 'Sub-Arctic Summer' for the 19 Nov image. The aerosol retrieval method implemented in FLAASH is the approach suggested by Kaufman et al. (1997), which involves selecting dark surface pixels in the image based on the at-sensor radiances at channels near $660 \mathrm{~nm}$ and $2100 \mathrm{~nm}$. Since AISA does not have a spectral channel near $2100 \mathrm{~nm}$, it was not possible to automatically retrieve aerosol properties from the image data using FLAASH. Instead, a fixed aerosol type and an initial assumption on the aerosol amount (supplied in the form of a visibility estimate) had to be fed as input parameters to FLAASH. The aerosol types considered were, 'No Aerosol', 'Rural Aerosol', and 'Tropospheric Aerosol'. The choice of aerosol seemed to primarily affect the magnitude of the retrieved reflectance, with no evident effect on its spectral shape. The aerosol type and amount were chosen so as to minimize the occurrence of negative values in the atmospherically corrected reflectances. Because the absorption features of principal atmospheric gases are welldefined and the concentrations of these gases are generally stable, the effects due to atmospheric absorption are usually well accounted for by atmospheric correction programs. Similarly, the effects of molecular Rayleigh scattering are also removed straightforwardly. However, removing the effects
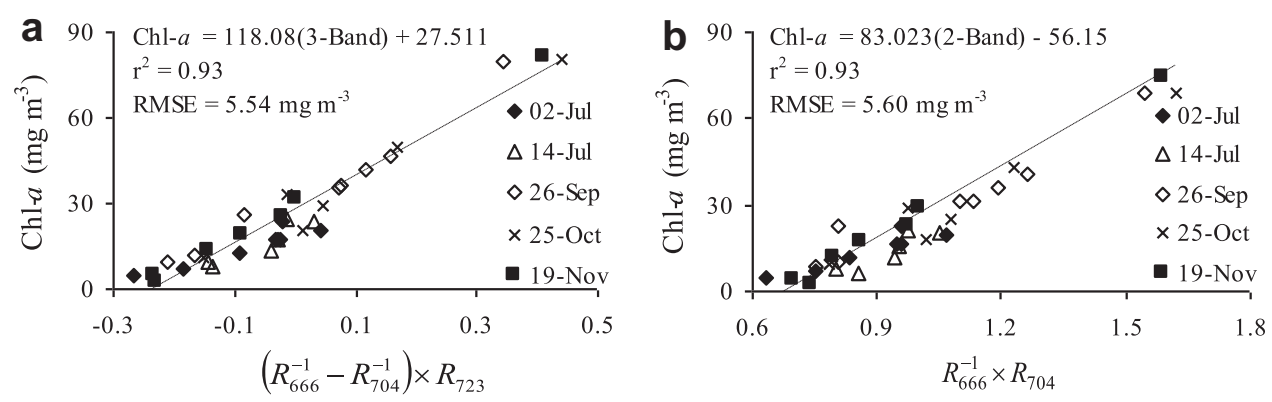

Fig. 5 - Plots of (a) three-band and (b) two-band NIR-red model values versus measured chl- $a$ concentration for the whole dataset after QUAC correction. $R_{x}$ is the reflectance in the spectral band centered at wavelength $x \mathrm{~nm}$. 

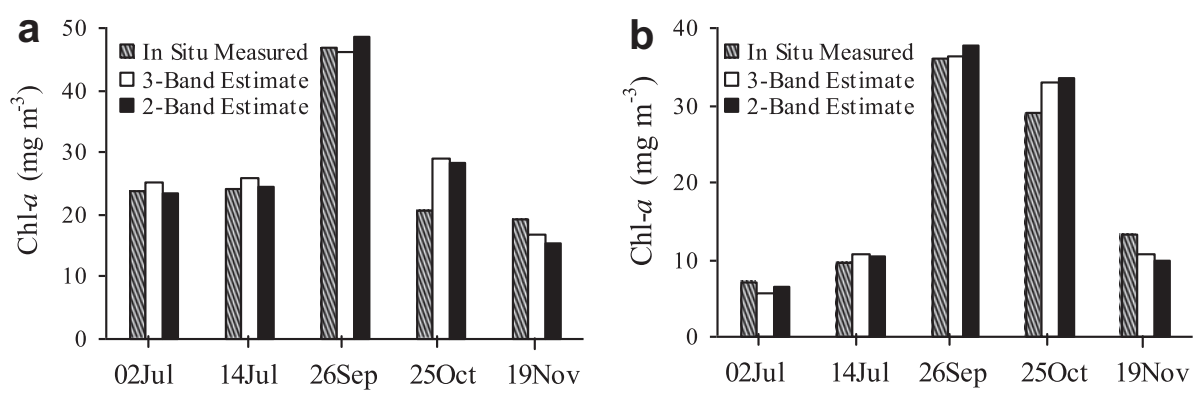

Fig. 6 - Temporal variation of chl-a concentration in the Fremont Lakes, (a) lake 02 and (b) lake 16 based on chla concentrations measured in situ and estimated by the three-band and two-band NIR-red algorithms applied to AISA imagery after QUAC correction. The estimates closely follow the temporal pattern obtained from actually measured chla concentrations.

due to scattering by atmospheric aerosols is challenging, and the input parameters that define the aerosol properties are crucial to obtaining accurate results.

The dimensionless FLAASH-corrected reflectances were converted to remote sensing reflectances through division by $\pi$. When the three-band (Eq. (4)) and two-band (Eq. (5)) NIR-red models were applied to FLAASH-corrected reflectances and the output compared with actually measured chl-a concentrations, the pattern of the results (Fig. 3) was very similar to what was obtained when the NIR-red models were applied to atmospherically uncorrected at-sensor reflectances (Figs. 2 and 3). For each individual image, there was a close correlation between the NIR-red model values and chl-a concentration but the slope and intercept of the linear regression varied across the dates (Fig. 3). This suggested that the non-uniform atmospheric effects on the multi-temporal imagery were not adequately removed by FLAASH. The RMSEs of the chla concentrations estimated using the three-band (Eq. (4)) and two-band (Eq. (5)) NIR-red models were, respectively, $7.68 \mathrm{mg} \mathrm{m} \mathrm{m}^{-3}$ (nRMSE $=9.73 \%$ ) and $7.34 \mathrm{mg} \mathrm{m}$ (nRMSE $=9.3 \%$ ), which are only slightly lower than those for reflectances without atmospheric correction (Fig. 2).

In most cases, the FLAASH-derived reflectance spectra poorly resembled typical reflectances from productive waters (Fig. 4). The magnitude of the output reflectance was very sensitive to the initial input atmospheric parameters. Irrespective of the aerosol model chosen, FLAASH seemed to over-correct for atmospheric scattering, resulting in considerably high negative reflectances at short wavelengths. Therefore, the aerosol input parameters were set so as to minimize the occurrence of negative reflectances. However, when compared to actual reflectance spectra measured in situ, it was evident that crucial reflectance features were distorted in the FLAASH-derived reflectance spectra, especially in the red and NIR regions (Fig. 4). There was also a significant difference in the magnitude of the reflectances, which can be attributed to potential differences in the radiometric characteristics between the Ocean Optics ${ }^{\circledR}$ spectrometer and the AISA sensor, and the erroneous removal of atmospheric scattering by FLAASH. Even though FLAASH is based on a wellestablished rigorous radiative transfer model, the output reflectance contained significant artifacts and the program seemed to over-correct for atmospheric scattering. Supplying input parameters based on actual measurements (for instance, aerosol optical depth measurements using a sun photometer) might help prevent the over-correction.

\subsection{QUAC atmospheric correction}

QUAC is fully image-driven and requires no atmospheric input parameters. Thus, it is simple and straightforward to execute. All five images were atmospherically corrected with QUAC. The dimensionless QUAC-corrected reflectances were converted to remote sensing reflectances through division by $\pi$, and the three-band (Eq. (4)) and two-band (Eq. (5)) NIR-red models were applied to the retrieved reflectance data. Not only were the linear relationships between the NIR-red model values and chl-a concentrations close for each campaign but the slopes and offsets of the relationship for the five days were also close to each other, resulting in a well-defined overall
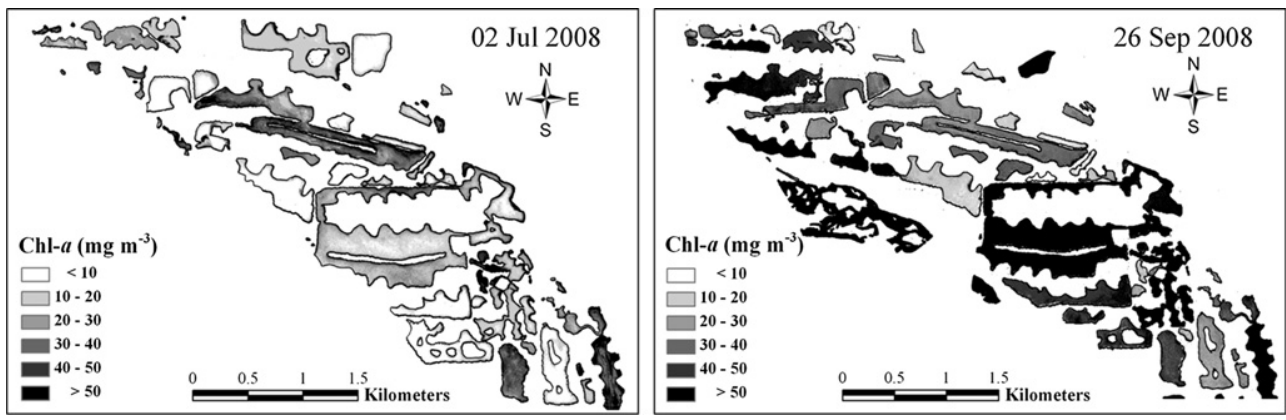

Fig. 7 - AISA-derived Chl-a maps of the Fremont State Lakes for 02 Jul and 26 Sep 08, produced using the two-band NIR-red algorithm (Eq. (8)). 

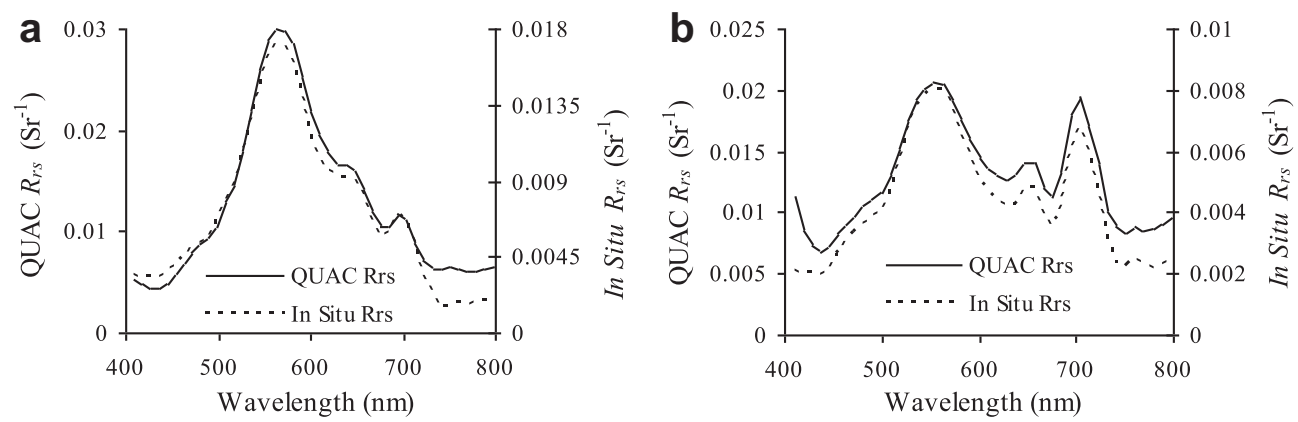

Fig. 8 - QUAC-corrected AISA reflectance (solid line) and reflectance measured in situ with the Ocean Optics ${ }^{\circledR}$ spectrometer (dotted line) for stations with (a) a moderate chl-a concentration (13.65 $\mathrm{mg} \mathrm{m}^{-3}$ ) and (b) a high chl-a concentration $\left(80.16 \mathrm{mg} \mathrm{m}^{-3}\right)$.

linear relationship (Fig. 5), with $r^{2}$ as high as 0.93. QUAC, which requires no information on the atmospheric conditions, seems to have adequately handled the non-uniform atmospheric effects, thus providing for a consistent relationship between the NIR-red model values and chl-a concentration across the five dates, which led to the following chla algorithms:

Chl- $a=118.08\left[\left(R_{666}^{-1}-R_{704}^{-1}\right) \times R_{723}\right]+27.511$

Chl- $a=83.023\left[R_{704} / R_{666}\right]-56.15$

These three-band (Eq. (7)) and two-band (Eq. (8)) NIR-red algorithms produced accurate quantitative estimates of chla concentration, with RMSEs of $5.54 \mathrm{mg} \mathrm{m}^{-3}$ (nRMSE $=7.02 \%$ ) and $5.60 \mathrm{mg} \mathrm{m}^{-3}$ (nRMSE $=7.1 \%$ ), respectively. The algorithms were also able to reliably capture the temporal variation of chl-a concentration in the lakes during the summer and fall of 2008 (Fig. 6). Chl-a maps produced using these algorithms captured the spatial and temporal variation and distribution of chl-a concentration in the Fremont Lakes during the period of data collection. For instance, the lakes underwent a significant change in their chl-a concentration between $02 \mathrm{Jul}$ and 26 Sep 08 (Fig. 7).

QUAC performed quite well in preserving the features of the reflectance spectra at both high and moderate chla concentrations (Fig. 8) even though there was often an offset in the magnitude when compared to the reflectances measured in situ by the Ocean Optics ${ }^{\circledR}$ field spectrometer, which can be partly attributed to the less-than-perfect removal of the path radiance and inherent differences in the radiometric characteristics between the AISA sensor and the Ocean Optics ${ }^{\circledR}$ spectrometer. The QUAC-derived reflectance spectra were smooth and the chlorophyll-specific spectral features were well preserved. This suggests that the simplistic assumptions implemented in QUAC (Bernstein et al., 2005a, b) hold true for this dataset and that QUAC is a reasonably viable atmospheric correction procedure.

\subsection{Airborne versus in situ estimates}

The slopes and offsets obtained for the relationships between the three-band (Eq. (4)) and two-band (Eq. (5)) NIR-red model values and chl-a concentration from the QUAC-corrected AISA reflectances (Equations (7) and (8)) were compared with the slopes and offsets obtained from in situ field spectrometer data on the same lakes (Fig. 9). The field spectrometer data yielded the following algorithms:

$$
\begin{aligned}
& \text { Chl- } a=119.28\left[\left(R_{666}^{-1}-R_{704}^{-1}\right) \times R_{723}\right]+18.399 \\
& \text { Chl- } a=72.874\left[R_{704} / R_{666}\right]-54.227
\end{aligned}
$$

The relationships between the NIR-red model values and chl-a concentration were reasonably similar for the QUACderived reflectances and in situ measured reflectances
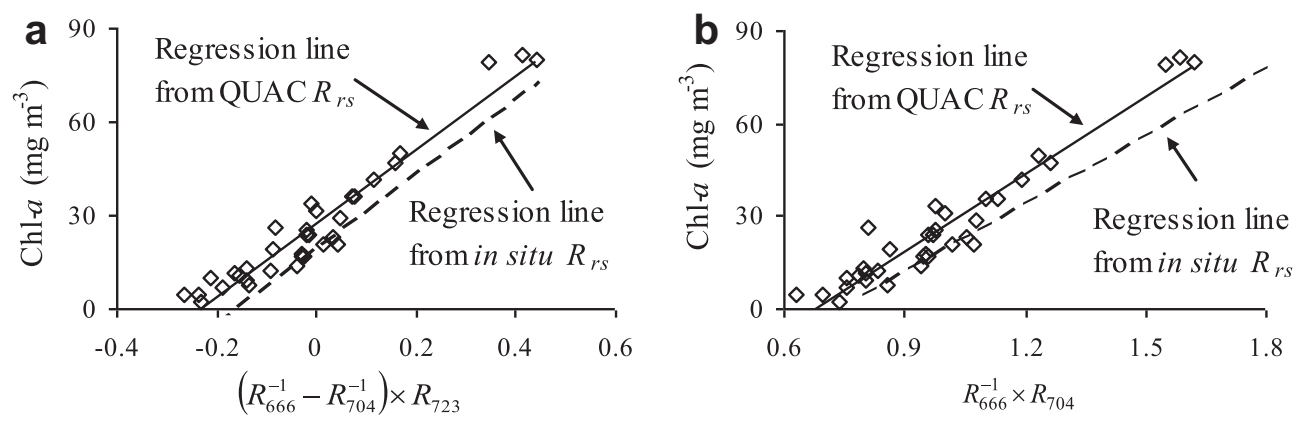

Fig. 9 - Linear relationships between measured chl- $a$ concentrations and (a) three-band and (b) two-band NIR-red model values for QUAC-corrected AISA reflectances (solid line) and reflectances measured in situ with the Ocean Optics ${ }^{\circledR}$ field spectrometer (dashed line). $R_{x}$ is the reflectance in the spectral band centered at wavelength $x$ nm. 
(Fig. 9). The differences in slope and offset are indicative of the residual effects of imperfect atmospheric correction of the AISA data in addition to the effects due to differences between the radiometric characteristics of the field spectrometer (Ocean Optics ${ }^{\circledR}$ USB, 2000) and the AISA sensor. When the three-band (Eq. (9)) and two-band (Eq. (10)) NIR-red algorithms were applied to in situ measured reflectances, the RMSEs of estimated chl- $a$ concentration were $3.94 \mathrm{mg} \mathrm{m} \mathrm{m}^{-3}$ $(\mathrm{nRMSE}=4.99 \%)$ and $5.02 \mathrm{mg} \mathrm{m}^{-3}$ (nRMSE $=6.36 \%$ ), respectively, which are marginally better than the corresponding figures for the QUAC-based algorithms (Equations (7) and (8)). The results show that QUAC has proven to be more reliable than FLAASH for this multi-temporal dataset. Even though FLAASH, which is based on a first-principles approach, is theoretically more sophisticated, its performance seems understandably highly dependent on its ability to accurately characterize the atmospheric aerosols. This is a major limitation when dealing with data from sensors such as AISA that do not have the spectral channels that are required for FLAASH's automatic aerosol retrieval, and there are no actual measurements of aerosol optical depth that can be supplied as input parameters. In such cases, QUAC produces a more reliable atmospheric correction when the dataset satisfactorily meets the underlying assumptions of QUAC (see Section 2.5 and Bernstein et al., 2005a, b). It should be noted that if the image does not meet these basic assumptions (for example, if there is limited spectral diversity or if there are no dark pixels), QUAC may produce inaccurate and unreliable results.

\section{Conclusion}

The three-band and two-band NIR-red models are reliable and yield highly accurate estimates of chl-a concentration in turbid productive waters using reflectance data collected by an airborne hyperspectral sensor. Even without atmospheric correction, the NIR-red models yield a close linear relationship with chl-a concentration and can be used to capture the spatial distribution of chl-a concentration in an aerial image.

However, if the dataset contains multi-temporal data with varying atmospheric effects on different days, it is necessary to use a robust atmospheric correction procedure to systematically remove the non-uniform atmospheric effects in the images. FLAASH and QUAC atmospheric correction procedures were tested. The theoretically more sophisticated FLAASH relies significantly on its ability to accurately characterize the atmospheric aerosol composition, which in this case was difficult because AISA did not have the spectral channels required for FLAASH's automatic aerosol retrieval and no actual measurements of atmospheric composition were available to correctly guide the program. QUAC, which is based on simple assumptions and does not require any knowledge of the atmospheric conditions, produced more consistent and reliable results, leading to the development of three-band and two-band NIR-red algorithms for estimating chl-a concentration from airborne data. In order to further validate these algorithms, the NIR-red models should be applied to more QUAC-corrected airborne images acquired over water bodies from different geographical locations and with a wider range of biogeochemical characteristics than what was encountered in the current dataset. If the relationship between the NIR-red model values and chl-a concentration remains consistently similar for numerous datasets, it will lead to the establishment of NIR-red algorithms that can be routinely applied to airborne data collected over turbid productive inland, estuarine, and coastal waters, without the need for regional adjustment of the model parameters. Such algorithms will be very effective tools in frequently monitoring these water bodies.

\section{Acknowledgments}

We would like to thank Yi Peng from the University of Nebraska-Lincoln for her technical support in the field and the laboratory. This research was supported by the NASA Land Cover Land Use Program grants NNG06GA92G and NNG06GG17G. This research was also supported in part by funds provided through the Hatch Act and contributions from the Agricultural Research Division at the University of Nebraska-Lincoln.

\section{R E F E R E N C E S}

Adler-Golden, S.M., Matthew, M.W., Bernstein, L.S., Levine, R.Y., Berk, A., Richtsmeier, S.C., Acharya, P.K., Anderson, G.P., Felde, G., Gardner, J., Hoke, M., Jeong, L.S., Pukall, B., Ratkowski, A., Burke, H.H., 1999. Atmospheric correction for shortwave spectral imagery based on MODTRAN4. In: SPIE Proceedings, Imaging Spectrometry, vol. 3753, pp. 61-69.

Austin, R.W., 1976. Air-water Radiance Calibration Factor, Tech. Memo. ML-76-004T, 8 pp.. Scripps Institution of Oceanography.

Berk, A., Anderson, G.P., Acharya, P.K., Chetwynd, J.H., Bernstein, L.S., Shettle, E.P., Matthew, M.W., AdlerGolden, S.M., 2000. MODTRAN4 User's Manual, Hanscom AFB: Air Force Research Laboratory, Space Vehicles Directorate, Air Force Material Command, MA 01731-3010, 97 pp.

Bernstein, L.S., Adler-Golden, S.M., Sundberg, R.L., Levine, R.Y., Perkins, T.C., Berk, A., Ratkowski, A.J., Felde, G., Hoke, M.L., 2005a. A new method for atmospheric correction and aerosol optical property retrieval for VIS-SWIR multi- and hyperspectral imaging sensors: QUAC (QUick atmospheric correction). In: Proceedings of the International Geoscience and Remote Sensing Symposium, IGARSS'05, 2005 IEEE International, vol. 5, pp. 3549-3552, 25-29 July 2005.

Bernstein, L.S., Adler-Golden, S.M., Sundberg, R.L., Levine, R.Y., Perkins, T.C., Berk, A., Ratkowski, A.J., Felde, G., Hoke, M.L., 2005b. Validation of the QUick Atmospheric Correction (QUAC) algorithm for VNIR-SWIR multi- and hyperspectral imagery. In: SPIE Proceedings, Algorithms and Technologies for Multispectral, Hyperspectral, and Ultraspectral Imagery XI, vol. 5806, pp. 668-678.

Bernstein, L.S., Adler-Golden, S.M., Sundberg, R.L., Ratkowski, A., 2006. Improved Reflectance Retrieval from Hyper- and Multispectral Imagery without Prior Scene or Sensor Information. In: SPIE Proceedings, Remote Sensing of Clouds and the Atmosphere XI, vol. 6362.

Carder, K.L., Chen, F.R., Cannizzaro, J.P., Campbell, J.W., Mitchell, B.G., 2004. Performance of the MODIS semi-analytical ocean color algorithm for chlorophyll-a. Climate Change Processes in the Stratosphere, Earth-Atmosphere-Ocean Systems, and Oceanographic Processes from Satellite Data 33 (7), 1152-1159. 
Dall'Olmo, G., Gitelson, A.A., 2005. Effect of bio-optical parameter variability on the remote estimation of chlorophylla concentration in turbid productive waters: experimental results. Applied Optics 44 (3), 412-422.

Dall'Olmo, G., Gitelson, A.A., Rundquist, D.C., 2003. Towards a unified approach for remote estimation of chlorophyll-a in both terrestrial vegetation and turbid productive waters. Geophysical Research Letters 30 (18), 1938. doi:10.1029/ 2003 GL018065.

Dall'Olmo, G., Gitelson, A.A., Rundquist, D.C., Leavitt, B., Barrow, T., Holz, J.C., 2005. Assessing the potential of SeaWiFS and MODIS for estimating chlorophyll concentration in turbid productive waters using red and near-infrared bands. Remote Sensing of Environment 96 (2), 176-187.

Dall'Olmo, G., Gitelson, A.A., 2006. Effect of bio-optical parameter variability on the remote estimation of chlorophylla concentration in turbid productive waters: modeling results. Applied Optics 45 (15), 3577-3592.

Darecki, M., Stramski, D., 2004. An evaluation of MODIS and SeaWiFS bio-optical algorithms in the Baltic Sea. Remote Sensing of Environment 89 (3), 326-350.

Dekker, A.G., 1993. Detection of Optical Water Quality Parameters for Eutrophic Waters by High Resolution Remote Sensing. Ph.D. Thesis. Amsterdam, Vrije Universiteit, p. 222.

Eaton, A.D., Clesceri, L.S., Rice, E.W., Greenberg, A.E., Franson, M.A.H. (Eds.), 2005. Standard Methods for the Examination of Water and Wastewater: Centennial Edition, first ed. American Public Health Association, Washington, D.C., ISBN 0875530478,1368 pp.

FLAASH Module User's Guide, 2008. FLAASH Module Version 4.5, ITT Visual Information Solutions.

Gilerson, A., Gitelson, A., Zhou, J., Ioannou, I., Ahmed, S., 2009. Remote Estimation of Chlorophyll-a in coastal waters using red and near infrared spectral regions. In: Proceedings of the V International Conference "Current Problems in Optics of Natural Waters (ONW)". St Petersburg, Russia, 8-11 September 2009, pp. 110-114.

Gilerson, A., Gitelson, A., Zhou, J., Gurlin, D., Moses, W., Ioannou, I., Ahmed, S., 2010. Algorithms for remote estimation of chlorophyll-a in coastal and inland waters using red and near infrared bands. Optics Express 18 (23), 24109-24125.

Gitelson, A., 1992. The peak near $700 \mathrm{~nm}$ on radiance spectra of Algae and water - relationships of its magnitude and position with chlorophyll concentration. International Journal of Remote Sensing 13 (17), 3367-3373.

Gitelson, A.A., Kondratyev, K.Y., 1991. On the mechanism of formation of maximum in the reflectance spectra near $700 \mathrm{~nm}$ and its application for remote monitoring of water quality. Transactions Doklady of the USSR Academy of Sciences: Earth Science Sections 306, 1-4.

Gitelson, A.A., Dall'Olmo, G., Moses, W., Rundquist, D.C., Barrow, T., Fisher, T.R., Gurlin, D., Holz, J., 2008. A simple semi-analytical model for remote estimation of chlorophylla in turbid waters: validation. Remote Sensing of Environment 112 (9), 3582-3593.

Gitelson, A., Gurlin, D., Moses, W., Barrow, T., 2009. A bio-optical algorithm for the remote estimation of the chlorophylla concentration in case 2 waters. Environmental Research Letters 4 (045003), 5.

Gitelson, A.A., Gurlin, D., Moses, W.J., Yacobi, Y.Z., 2011. Remote Estimation of Chlorophyll-a Concentration in Inland, Estuarine, and Coastal Waters, pp. 449-478. In: Weng, Q. (Ed.), Advances in Environmental Remote Sensing: Sensors, Algorithms, and Applications, ISBN 9781420091755, p. 584.

Gons, H.J., 1999. Optical teledetection of chlorophyll a in turbid inland waters. Environmental Science \& Technology 33 (7), 1127-1132.
Gordon, H.R., Morel, A.Y., 1983. Remote Assessment of Ocean Color for Interpretation of Satellite Visible Imagery: A Review. Springer-Verlag, New York.

Gordon, H.R., Brown, O.B., Evans, R.H., Brown, J.W., Smith, R.C., Baker, K.S., Clark, D.K., 1988. A semianalytic radiance model of ocean color. Journal of Geophysical Research 93, 10909-10924.

Gower, J.F.R., Doerffer, R., Borstad, G.A., 1999. Interpretation of the $685 \mathrm{~nm}$ peak in water-leaving radiance spectra in terms of fluorescence, absorption and scattering, and its observation by MERIS. International Journal of Remote Sensing 20 (9), 1771-1786.

Gurlin, D., Gitelson, A.A., Moses, W.J., 2011. Remote estimation of chl-a concentration in turbid productive waters - return to a simple two-band NIR-red model? Remote Sensing of Environment 115 (12), 3479-3490.

Han, L.H., Rundquist, D.C., 1997. Comparison of NIR/RED ratio and first derivative of reflectance in estimating algal-chlorophyll concentration: a case study in a turbid reservoir. Remote Sensing of Environment 62 (3), 253-261.

Han, L., Rundquist, D.C., Liu, L.L., Fraser, R.N., Schalles, J.F., 1994. The spectral responses of algal chlorophyll in water with varying levels of suspended sediment. International Journal of Remote Sensing 15 (18), 3707-3718.

Honeywill, C., Paterson, D.M., Hegerthey, S.E., 2002. Determination of microphytobenthic biomass using pulseamplitude modulated minimum fluorescence. European Journal of Phycology 37 (4), 485-492.

Kallio, K., Kutser, T., Hannonen, T., Koponen, S., Pulliainen, J., Vepsaälaäinen, J., Pyhaälahti, T., 2001. Retrieval of water quality from airorne imaging spectrometry of various lake types in different seasons. The Science of the Total Environment 268 (1-3), 59-77.

Kaufman, Y.J., Wald, A.E., Remer, L.A., Gao, B.C., Li, R.R., Flynn, L., 1997. The MODIS 2.1- $\mu \mathrm{m}$ channel - correlation with visible reflectance for use in remote sensing of aerosol. IEEE Transactions on Geoscience and Remote Sensing 35 (5), 1286-1298.

Koponen, S., Pulliainen, J., Kallio, K., Hallikainen, M., 2002. Lake water quality classification with airborne hyperspectral spectrometer and simulated MERIS data. Remote Sensing of Environment 79 (1), 51-59.

Matthew, M.W., Adler-Golden, S.M., Berk, A., Richtsmeier, S.C. Levine, R.Y., Bernstein, L.S., Acharya, P.K., Anderson, G.P., Felde, G.W., Hoke, M.P., Ratkowski, A., Burke, H.H., Kaiser, R.D., Miller, D.P., 2000. Status of atmospheric correction using a MODTRAN4-based algorithm. In: SPIE Proceedings, Algorithms for Multispectral, Hyperspectral, and Ultraspectral Imagery VI, vol. 4049, pp. 199-207.

Matthew, M.W., Adler-Golden, S.M., Berk, A., Felde, G., Anderson, G.P., Gorodetzky, D., Paswaters, S., Shippert, M., 2002. Atmospheric correction of spectral imagery: evaluation of the FLAASH algorithm with AVIRIS data. In: Proceedings of 31st Applied Imagery Pattern Recognition Workshop. IEEE Computer Society, Washington, D.C., pp. 157-163.

Mitchell, B.G., Kahru, M., Wieland, J., Stramska, M., 2003. Determination of spectral absorption coefficients of particles, dissolved material and phytoplankton for discrete water samples. In: Mueller, J.L., Fargion, G.S., McClain, C.R. (eds.), Inherent Optical Properties: Instruments, Characterizations, Field Measurements and Data Analysis Protocols, Ocean Optics Protocols for Satellite Ocean Color Sensor Validation, Revision 4, vol. IV, NASA Technical Memorandum 2003211621, NASA Goddard Space Flight Center, MD.

Morel, A., Prieur, L., 1977. Analysis of variations in ocean color. Limnology and Oceanography 22 (4), 709-722.

Moses, W.J., 2009. Satellite-based estimation of chlorophylla concentration in turbid productive waters. PhD diss., University of Nebraska-Lincoln, Lincoln, NE. 
Moses, W.J., Gitelson, A.A., Berdnikov, S., Povazhnyy, V., 2009a. Estimation of chlorophyll-a concentration in case II waters using MODIS and MERIS data-successes and challenges. Environmental Research Letters 4 (045005), 8.

Moses, W., Gitelson, A., Berdnikov, S., Povazhnyy, V., 2009b. Satellite estimation of chlorophyll-a concentration using the red and NIR bands of MERIS - the AzovSea case study. IEEE Geoscience and Remote Sensing Letters 4 (6), 845-849.

Mueller, J.L., Austin, R.W., 1995. Ocean Optics Protocols for SeaWiFS Validation, Revision 1. SeaWiFS Technical Report Series. In: NASA Technical Memorandum 104566, vol. 25. NASA Goddard Space Flight Center, MD.

NDEQ Water Quality Division, 2010. 2010 Water Quality Integrated Report. NDEQ Integrated Reports. Nebraska Department of Environmental Quality, Nebraska, USA.

O’Reilly, J.E., Maritorena, S., Mitchell, B.G., Siegel, D.A., Carder, K.L., Garver, S.A., Kahru, M., McClain, C., 1998. Ocean color chlorophyll algorithms for SeaWiFS. Journal of Geophysical Research-Oceans 103 (C11), 24937-24953.

O'Reilly, J.E., et al., 2000. SeaWiFS Postlaunch Calibration and Validation Analyses, Part 3. In: NASA Tech. Memo. 2000206892, vol. 11. NASA Goddard Space Flight Center, MD. 49.

Ohde, T., Siegel, H., 2003. Derivation of immersion factors for the hyperspectral Trios radiance sensor. Journal of Optics A Pure and Applied Optics 5 (3), L12-L14.
Revenga, C., Kura, Y., 2003. Status and Trends of Biodiversity of Inland Water Ecosystems. Secretariat of the Convention on Biological Diversity, Montreal.

Ruddick, K.G., Gons, H.J., Rijkeboer, M., Tilstone, G., 2001. Optical remote sensing of chlorophyll-a in case 2 waters by use of an adaptive two-band algorithm with optimal error properties. Applied Optics 40 (21), 3575-3585.

Schalles, J.F., Gitelson, A.A., Yacobi, Y.Z., Kroenke, A.E., 1998. Estimation of chlorophyll a from time series measurements of high spectral resolution reflectance in an eutrophic lake. Journal of Phycology 34 (2), 383-390.

Vasilkov, A., Kopelevich, O., 1982. Reasons for the appearance of the maximum near $700 \mathrm{~nm}$ in the radiance spectrum emitted by the ocean layer. Oceanology 22 (6), 697-701.

Welschmeyer, N.A., 1994. Fluorometric analysis of chlorophyll $\mathrm{a}$ in the presence of chlorophyll $\mathrm{b}$ and pheopigments. Limnology and Oceanography 39 (8), 1985-1992.

Yacobi, Y.Z., Moses, W.J., Kaganovsky, S., Sulimani, B., Leavitt, B.C., Gitelson, A.A., 2011. NIR-red reflectance-based algorithms for chlorophyll-a estimation in mesotrophic inland and coastal waters: lake Kinneret case study. Water Research 45 (7), 2428-2436.

Zibordi, G., 2006. Immersion factor of in-water radiance sensors: assessment for a class of radiometers. Journal of Atmospheric and Oceanic Technology 23 (2), 302-313. 